\title{
Seletividade de Herbicidas. II - Aplicação de Herbicidas em Pós-Emergência INicial E TARdia da CANA-De-Açúcar Na Época Das Chuvas ${ }^{1}$
}

\author{
Herbicide Selectivity. II - Herbicide Application at Initial and Late and Post-emergence of \\ Sugarcane in the Rainy Season
}

AZANIA, C.A.M. ${ }^{2}$, ROLIM, J.C. ${ }^{3}$, CASAGRANDE, A.A. ${ }^{4}$, LAVORENTI, N.A. ${ }^{5}$ e AZANIA, A.A.P.M. ${ }^{6}$

\begin{abstract}
RESUMO - Objetivou-se com este trabalho testar a seletividade dos herbicidas diuron+hexazinone, azafenidin+hexazinone, metribuzin e isoxaflutole, aplicados em pósemergência inicial e tardia das plantas de cana-de-açúcar, cultivar RB835089, na época das chuvas, em soqueira de terceiro corte, após colheita com queima prévia do canavial, em Araras-SP. O delineamento experimental foi o de blocos casualizados com testemunhas pareadas, com cinco tratamentos e quatro repetições, existindo uma testemunha capinada para cada tratamento químico dentro de cada bloco. Os tratamentos foram: diuron+hexazinone $\left(1.170+330 \mathrm{~g} \mathrm{ha}^{-1}\right)$, azafenidin+hexazinone $\left(192,5+247,5 \mathrm{~g} \mathrm{ha}^{-1}\right)$, metribuzin $\left(1.920 \mathrm{~g} \mathrm{ha}^{-1}\right)$, isoxaflutole $\left(127,5 \mathrm{~g} \mathrm{ha}^{-1}\right)$ e testemunha. Concluiu-se que os herbicidas foram mais fitotóxicos quando aplicados na pós-emergência tardia. Em pós-emergência inicial, o isoxaflutole foi o único produto que afetou a produtividade agrícola. Na pós-emergência tardia, todos os herbicidas prejudicaram a produtividade agrícola, sendo o diuron+hexazinone o único produto que não afetou as características tecnológicas e o rendimento de açúcar.
\end{abstract}

Palavras-chave: Saccharum spp., herbicidas, seletividade, plantas daninhas.

ABSTRACT - This research aimed to evaluate the selectivity of azafenidin+hexazinone, diuronthexazinone, metribuzin and isoxaflutole to sugarcane, applied at initial and late post-emergence during the rainy season. The study was conducted over 3-yr sugarcane ratoons (cv. RB 835089), in Araras, SP. The experiment was arranged in randomized blocks with five treatments and four replications, and one weeded control for each treatment within each block. The treatments used were: (diuronthexazinone $\left(1,170+330 \mathrm{~g} \mathrm{ha}^{-1}\right)$, azafenidin+hexazinone $\left(192.5+247.5 \mathrm{~g} \mathrm{ha}^{-1}\right)$, metribuzin $\left(1,920 \mathrm{~g} \mathrm{ha}^{-1}\right)$ and isoxaflutole (127.5 $\left.\mathrm{g} \mathrm{ha}^{-1}\right)$ and weed control. It was concluded that the herbicides damaged sugarcane the most when applied during late post-emergence. At early post-emergence, isoxaflutole was the only herbicide affecting yield. In late post-emergence, all the herbicides affected yield, with diuron+hexazinone being the only one that did not affect sugarcane technological characteristics and yield

Key words: Saccharum spp., herbicides, selectivity, weeds.

\section{INTRODUÇÃO}

No período de chuvas, época de maior ocorrência de plantas daninhas (Azzi \& Fernandes, 1968), o controle químico pode ser realizado em pós-emergência inicial ou tardia, em função de atraso nas operações de cultivo das soqueiras de cana-de-açúcar e da impossibilidade de aplicação de herbicidas na préemergência da cultura e das plantas daninhas, decorrente do excesso de chuvas que pode ocorrer no período. Na condição de aplicação

Recebido para publicação em 11/4/2005 e na forma revisada em 25/11/2005.

Pqc. I Dr., Instituto Agronômico/Centro Cana, Rod. Anel Viário Contorno Sul, km 321, Caixa Postal 206, 14001-970 Ribeirão Preto-SP. ${ }^{3}$ Prof. Dr. do CCA/UFSCar. ${ }^{4}$ Prof. Dr. da FCAVJ/UNESP. ${ }^{5}$ Prof. Dr. do CCA/UFSCar. ${ }^{6}$ Doutoranda em Produção Vegetal na FCAVJ/UNESP. 
em pós-emergência das plantas de cana-deaçúcar, a seletividade dos herbicidas tornase um fator muito importante, porque as injúrias por eles causadas podem ser mais severas.

Clement et al. (1979) detectaram que a mistura formulada diuron+hexazinone não prejudicou a produção final e as características tecnológicas da cana-de-açúcar. Para Costa \& Rozanski (2003), o isoxaflutole e o diuron+hexazinone causaram sintomas de intoxicação de cerca de $14 \%$ até os 60 dias após aplicação (DAA) e menor produção final; também foi constatado por Christoffoleti et al. (1997) que os mesmos produtos causaram leves sintomas de intoxicação até os 29 DAA, com total recuperação posterior. Por sua vez, a mistura formulada azafenidin+hexazinone, o metribuzin e o isoxaflutole não causaram prejuízos no crescimento, na produtividade e nas características tecnológicas da cultura (Negrisoli, 2002).

Outras pesquisas mostraram que o metribuzin proporcionou maior estande, maior altura, menores sintomas de intoxicação, maior produção e rendimento de açúcar (Richard Jr, 1996, 1998). Cruz \& Gurgell (1983) detectaram que o metribuzin foi fitotóxico até os 53 DAA, porém não prejudicou as características tecnológicas e a produção final.

Com relação à mistura pronta diuron+ hexazinone, Victoria Filho \& Camargo (1980) não encontraram prejuízos na produção e nas características tecnológicas da matéria-prima, confirmando dados obtidos por Mello Filho et al. (1986), que não observaram sintomas severos quando se testou o produto em solos arenosos, médios e argilosos. Para o isoxaflutole, aplicado isoladamente ou em mistura com o ametrine, observou-se queimadura dos ponteiros das folhas e redução da altura de plantas até os 63 DAA (Durigan et al., 1997).

Com o objetivo de contribuir com mais informações sobre o tema, foi desenvolvido o presente trabalho, a fim de verificar a seletividade dos herbicidas aplicados em pósemergência inicial e tardia da cana-de-açúcar, na época de maior pluviosidade, utilizando o delineamento experimental de blocos casualizados com testemunhas pareadas (Azania, 2004).

Planta Daninha, Viçosa-MG, v. 23, n. 4, p. 669-675, 2005

\section{MATERIAL E MÉTODOS}

O experimento foi instalado no município de Araras, SP, em solo de textura muito argilosa (61\% argila, $24 \%$ de areia e $15 \%$ de silte), previamente calcareado e adubado, de acordo com o resultado da análise de solo, a fim de atender às necessidades nutricionais da cana-de-açúcar, soqueira de terceiro corte, cultivar RB835089.

A aplicação dos herbicidas foi feita em dois momentos, constituindo duas áreas experimentais específicas. Na primeira área experimental, a aplicação dos herbicidas foi efetuada em pós-emergência inicial da canade-açúcar em 6/11/2001, aos 27 dias após a colheita da segunda soca, ocasião em que as plantas apresentavam-se com 10,68 cm de altura (do solo até dew-lap), em média. Na segunda área experimental, a aplicação dos produtos foi realizada em pós-emergência tardia das plantas em 4/12/2001, aos 55 dias após a colheita, com as plantas apresentando, em média, 29,50 cm de altura.

Os tratamentos, em ambas as situações, foram constituídos pela aplicação de diuron+ hexazinone $\left(1.170+330 \mathrm{~g} \mathrm{ha}^{-1}\right)$, azafenidin+ hexazinone $\left(192,5+247,5 \mathrm{~g} \mathrm{ha}^{-1}\right)$, metribuzin (1.920 $\left.\mathrm{g} \mathrm{ha}^{-1}\right)$ e isoxaflutole $\left(127,5 \mathrm{~g} \mathrm{ha}^{-1}\right)$, existindo ainda uma testemunha; todas as parcelas foram mantidas livres da presença de plantas daninhas durante todo o experimento. Para aplicação utilizou-se equipamento costal pressurizado $\left(\mathrm{CO}_{2}\right)$, munido de barra com três bicos Teejet DG $110.02 \mathrm{VS}$, espaçados de $0,50 \mathrm{~m}$, com pressão de 35 libras pol-2 e volume de calda de $250 \mathrm{~L} \mathrm{ha}^{-1}$.

O delineamento experimental utilizado em cada área experimental foi o de blocos casualizados, com cinco tratamentos e quatro repetições, salientando-se que havia uma testemunha para cada tratamento químico, dentro de cada bloco (delineamento em blocos casualizados com testemunhas pareadas), segundo metodologia proposta por Azania (2004). Existiam, então, em cada área experimental, 16 parcelas tratadas com herbicidas e 16 parcelas testemunhas, colocadas pareadas a cada tratamento químico. As parcelas foram constituídas de cinco linhas de cana-de-açúcar com $10 \mathrm{~m}$ de comprimento, espaçadas de $1,30 \mathrm{~m}$, sendo 
consideradas úteis as três linhas centrais $\left(39 \mathrm{~m}^{2}\right)$.

A seletividade dos herbicidas às plantas de cana-de-açúcar foi avaliada visualmente aos 15, 30, 45 e 60 dias após aplicação (DAA), nas três linhas centrais de cada parcela, sendo atribuídas notas percentuais, utilizando-se uma escala variando de 0 a $100 \%$, sendo $0 \%$ nenhuma injúria e $100 \%$ morte total das plantas.

$\mathrm{Na}$ área útil de cada parcela também foram avaliados aos 30, 45 e 60 DAA: a altura de 10 plantas escolhidas ao acaso; o teor de clorofila total nas folhas (expresso em unidades relativas - UR), empregando-se clorofilômetro de campo Mod. Spad 502 Minolta, no terço médio da folha +3 de seis plantas escolhidas ao acaso; e o índice de fluorescência $(\mathrm{Fv} / \mathrm{Fm})$, empregando-se o fluorômetro portátil (PEA "Plant Efficiency Analyser" Hansatech), também no terço médio da folha +3 de seis plantas escolhidas ao acaso. Também foi determinado o número de colmos da área útil das parcelas, aos 90 e 180 DAA.

Por ocasião da colheita, aos 273 DAA para condição de pós-emergência inicial e 245 DAA para pós-emergência tardia, os valores percentuais de Brix\%caldo, Pol\%caldo, Pureza\%caldo, Fibra\%cana, Açúcares Redutores\%caldo e Açúcar Teórico Recuperável\%caldo (ATR) foram determinados em laboratório, por amostragem de 10 colmos retirados da linha central de cada parcela. O peso dos colmos das três linhas centrais de todas as parcelas foi avaliado, a fim de se determinar a produtividade agrícola (t ha-1).

Os dados obtidos foram submetidos à análise de variância; para comparação das médias dos tratamentos foi utilizado o teste "t" a 5\% de probabilidade, segundo metodologia de Azania (2004).

\section{RESULTADOS E DISCUSSÃO}

\section{Aplicação em pós-emergência inicial}

No experimento em que houve aplicação dos herbicidas em pós-emergência inicial da soqueira, considerando o período entre 15 e 60 DAA, o isoxaflutole proporcionou os maiores sintomas de intoxicação nas plantas de cana-de-açúcar, decrescentes ao longo do tempo (Figura 1), resultados estes similares aos encontrados por Durigan et al. (1997) e por Christoffoleti et al. (1997).

Segundo Rodrigues \& Almeida (2005), o isoxaflutole possui baixa mobilidade na maioria dos solos, podendo esse fato ter contribuído para a concentração do herbicida nas camadas superficiais e, conseqüentemente, possibilitado o maior contato dos brotos da soqueira com o herbicida, causando os sintomas de intoxicação observados na Figura 1.

Quanto à altura (Tabela 1), pode-se observar que as plantas aos 45 DAA foram prejudicadas pelo azafenidin+hexazinone e pelo isoxaflutole, havendo, porém, total recuperação aos 60 DAA.

$O$ índice de fluorescência, nas folhas da cana-de-açúcar, aos 30 DAA foi significativamente reduzido por azafenidin+hexazinone; aos 45 e 60 DAA, também o diuron+hexazinone influenciou negativamente este indice (Tabela 1). Deve-se salientar, porém, que as diferenças ocorridas no índice de fluorescência não foram muito prejudiciais ao aparato fotossintético, pois a média dos dados originais dos tratamentos apresentou-se com índice de fluorescência $(\mathrm{Fv} / \mathrm{Fm})$ entre 0,72 e 0,78;

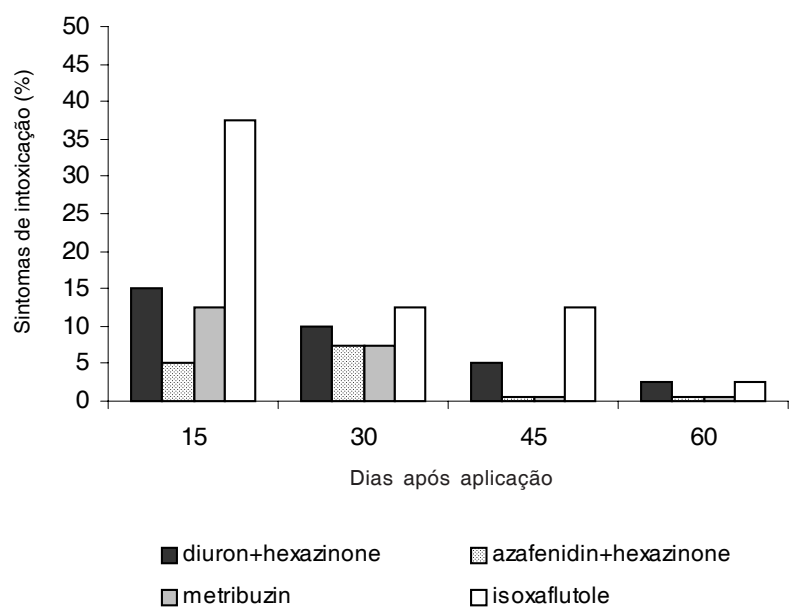

Figura 1 - Percentuais de sintomas de intoxicação atribuídos às plantas de cana-de-açúcar aos $15,30,45$ e 60 DAA por diuron+hexazinone, azafenidin+hexazinone, metribuzin e isoxaflutole, na aplicação em pós-emergência inicial da soqueira (cultivar RB83 5089). Araras-SP, 2003.

Planta Daninha, Viçosa-MG, v. 23, n. 4, p. 669-675, 2005 
Cechin (1996) apresentou indices de fluorescência normais de 0,8 para a maioria das culturas. Segundo este autor, a diminuição da razão entre a fluorescência variável máxima $(\mathrm{Fv})$ e a fluorescência total máxima $(\mathrm{Fm})$ indica

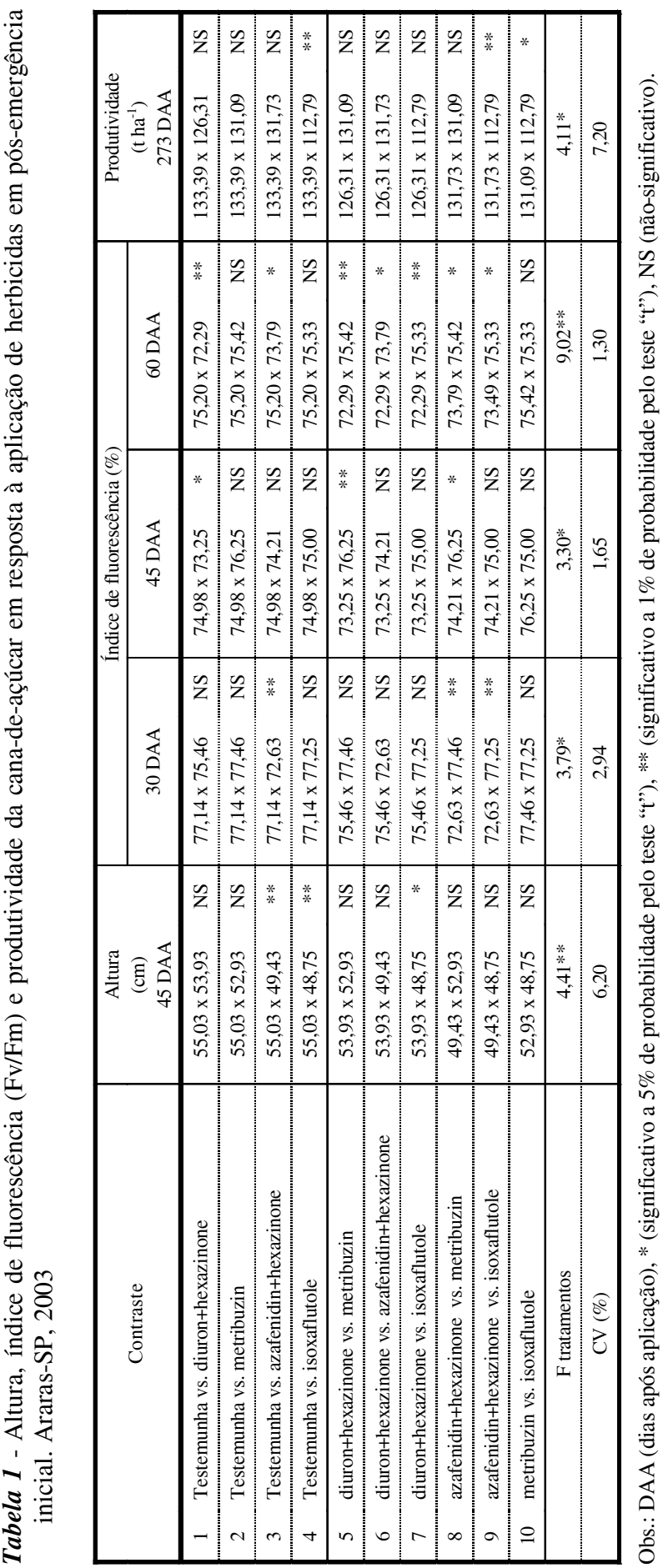

que algum fator ambiental pode estar interferindo na eficiência do fotossistema II.

O isoxaflutole reduziu significativamente a produtividade da cana-de-açúcar em relação ao tratamento testemunha, azafenidin+ hexazinone e metribuzin (Tabela 1). Esses resultados contrariam aqueles observados por Negrisoli (2002), o qual verificou que o isoxaflutole não apresentou prejuízos em crescimento, produtividade e características tecnológicas da cana-de-açúcar. Essa diferença pode ser devida às diferenças entre cultivares, tipo de solo e condições climáticas e à maior sensibilidade, conforme Azania (2004), do delineamento em blocos com testemunhas pareadas adotado neste experimento.

\section{Aplicação em pós-emergência tardia}

Foram observados, nos primeiros 15 DAA, sintomas de fitotoxicidade maiores nos tratamentos com azafenidin+hexazinone, isoxaflutole e diuron+hexazinone (Figura 2); as plantas tiveram, a partir desse período, recuperação progressiva ao longo do tempo. Esse resultado pode estar associado ao maior porte das plantas, as quais possivelmente tiveram maior contato com o herbicida no momento da aplicação. A recuperação da cultura pode estar relacionada com a mobilidade do herbicida no solo (Anvisa, 2003) e sua possivel distribuição pelo perfil, em função das

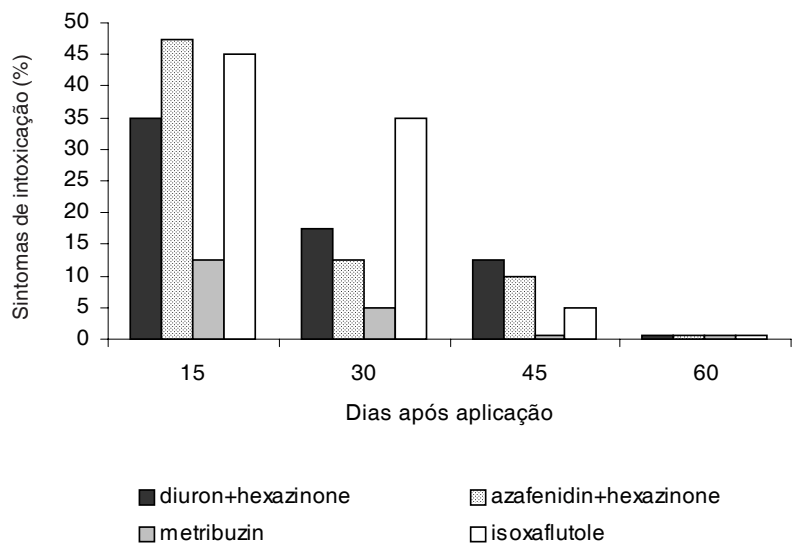

Figura 2 - Percentuais de sintomas de intoxicação atribuídos às plantas de cana-de-açúcar aos $15,30,45$ e 60 DAA por diuron+hexazinone, azafenidin+hexazinone, metribuzin e isoxaflutole, na aplicação em pós-emergência tardia da soqueira (cultivar RB835089). Araras-SP, 2003. 
chuvas, diminuindo os sintomas de intoxicação na cultura. Esses herbicidas também causaram redução na altura e no estande (Tabela 2), salientando-se que o estande aos 180 DAA não foi possível de ser avaliado, devido ao acamamento dos colmos.

O teor de clorofila total determinado aos 30 DAA somente não foi afetado pelo azafenidin+hexazinone, quando comparado com a testemunha, como se pode observar na Tabela 2. O índice de fluorescência aos 30 e 45 DAA, assim como foi detectado na condição de aplicação em pós-emergência inicial (Tabela 1), também foi prejudicado por diuron+hexazinone e azafenidin+hexazinone, porém os resultados obtidos indicam não ter havido prejuízo drástico ao aparato fotossintético, conforme Cechin (1996).

A aplicação dos herbicidas em pós-emergência tardia prejudicou a qualidade da matéria-prima (Brix\%caldo, Pureza\%caldo e AR\%caldo) e a produtividade da cana-de-açúcar (Tabela 3). Pela análise dos dados desta tabela, verifica-se que todos os herbicidas prejudicaram a produtividade agrícola e, com exceção do diuron+hexazinone, afetaram os teores de brix, pureza, açúcares redutores e açúcar teórico recuperável do caldo. Esses resultados podem estar relacionados principalmente aos elevados sintomas de intoxicação observados até os 45 DAA, aos prejuízos à altura das plantas até os 60 DAA e ao estande do canavial aos 90 DAA. Acredita-se que o maior porte das plantas de cana-de-açúcar por ocasião da aplicação dos produtos, caracterizando uma fase metabólica bastante intensa e de maior suscetibilidade aos herbicidas, tenha sido fator predisponente aos sintomas de injúrias mais acentuados e prejuízos causados pelos herbicidas na cultura.

Os resultados experimentais obtidos permitem concluir que, na condição de aplicação em pós-emergência inicial, o isoxaflutole foi o produto mais fitotóxico, chegando a prejudicar a produtividade agrícola. Na condição de aplicação em pós-emergência tardia, somente o metribuzin não causou sintomas de intoxicação mais severos, porém todos os herbicidas prejudicaram a produtividade agrícola; diuron+ hexazinone foi o único produto que não afetou as características tecnológicas da matériaprima final e o rendimento de açúcar.

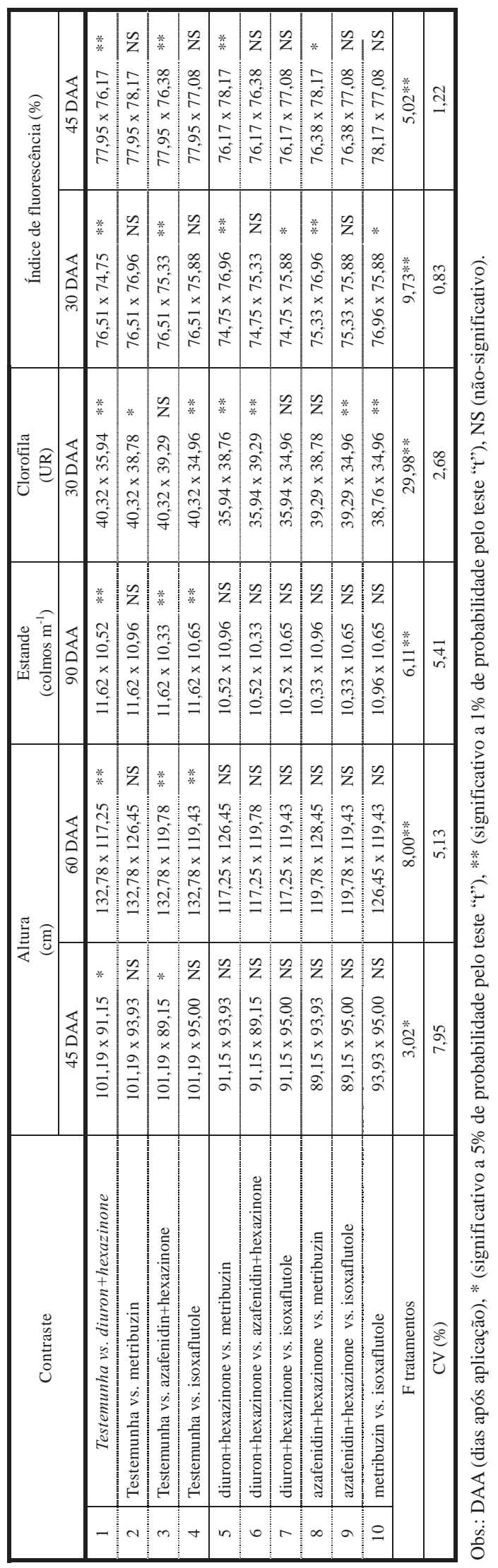




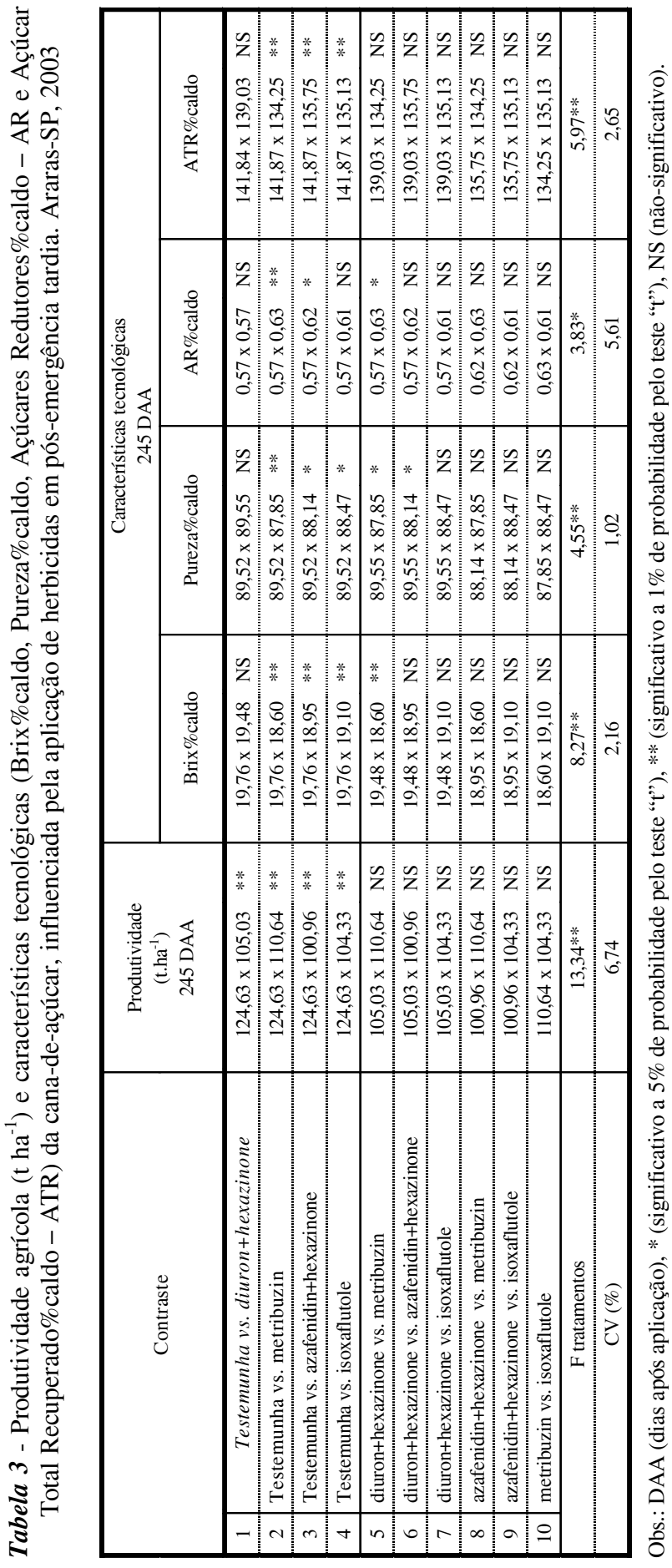

\section{AGRADECIMENTO}

À Cooperativa dos Fornecedores de Cana de Piracicaba (AFOCAPI), em especial ao Eng.Agr. Marcos Fahrat e aos proprietários rurais Irineu, Walter e Percival Pastre e, especialmente, ao Eng.-Agr. Waldinei Pastre.

\section{LITERATURA CITADA}

AGÊNCIA NACIONAL DE VIGILÂNCIA SANITÁRIA ANVISA. SAI - Sistema de informação sobre agrotóxicos. Disponível em:<http://www4.anvisa.gov..br>. Acesso em: 4 out. 2003.

AZZI, G. M.; FERNANDES, J. Competição de ervas daninhas no período inicial de desenvolvimento da cana-deaçúcar. Brasil Açuc., v. 72, n. 3, p. 9-19, 1968.

AZANIA, C. A. M. Comparação de métodos para determinar a seletividade de herbicidas na cultura na cultura da cana-de-açúcar. 2004. 116 f. Tese (Doutorado em Produção Vegetal) - Universidade Estadual Paulista, Jaboticabal, 2004.

CECHIN, I. Uso de sistemas portáteis de fluorescência na avaliação do estresse. In: CONGRESSO DA SOCIEDADE BOTÂNICA DE SÃO PAULO, 20., 1996, São Carlos. Anais... São Carlos: Universidade Federal de São Carlos, 1996. p. 1-28.

CHRISTOFFOLETI, P. J.; ZAMBON, S.; BIAZOTTO, I. L. Avaliação do herbicida isoxaflutole aplicado isolado ou em mistura de tanque no controle pré-emergente de plantas daninhas em soqueira de cana-de-açúcar. In: CONGRESSO BRASILEIRO DA CIÊNCIA DAS PLANTAS DANINHAS, 21., 1997, Caxambu. Resumos... Caxambu: SBCPD, 1997. p. 255.

CLEMENT, A. A.; LAMMEL, J. S.; BARBOSA, J. C. Controle de plantas daninhas em cana-de-açúcar (Saccharum officinarum) com hexazinone e suas misturas com diuron, em pré-emergência. Planta Daninha, v. 2, p. 85-88, 1979.

COSTA, E. A. D.; ROZANSKI, A. Eficácia da aplicação sequiencial de isoxaflutole associado com ametryn ou diuron no controle de plantas daninhas em cana-de-açúcar. B. Inf. SBCPD, v. 9, n. 1, p. 14-20, 2003.

CRUZ, L. S. P.; GURGELL, M. N. A. Efeito de hexazinone e diuron, e suas misturas, no controle de capim-colchão (Digitaria sanguinalis) em cana-de-açúcar (Saccharum spp.). Planta Daninha, v. 1, p. 15-20, 1983.

DURIGAN, J. C.; PRETTO, D. R.; LEITE, G. J.

Seletividade de isoxaflutole isolado e em mistura de tanque aplicado na cultura da cana-de-açúcar. In: CONGRESSO BRASILEIRO DA CIÊNCIA DAS PLANTAS DANINHAS, 21., 1997, Caxambu. Resumos... Caxambu: SBCPD, 1997. p. 257.

MELLO FILHO, A. T. et al. Estudo comparativo de herbicidas de pós-emergência para o controle de plantas daninhas na cana-de-açúcar. STAB: Açúc., Álcool Subp., v. 5, n. 1, p. 32-36, 1986. 
NEGRISOLI, E. Seletividade de herbicidas aplicados em pré-emergência e associados a nematicidas, à cultura da cana-de-açúcar, cultivar RB855113. 2002. 48 f. Dissertação (Mestrado em Agricultura) - Universidade Estadual Paulista, Botucatu, 2002.

RODRIGUES, B. N.; ALMEIDA, F. S. In: Guia de herbicidas. 5.ed. Londrina: 2005. 592 p.

RICHARD JR., E. P. Sugarcane (Saccharum spp. hybrids) tolerance to clomazone. Weed Technol., v. 10, p. 90-94, 1996.
RICHARD JR., E. P. Control of perennated bermudagrass (Cynodon dactylon) and johnsongrass (Sorghum halepense) in sugarcane (Saccharum spp. hybrids). Weed Technol., v. 12, p. $128-133,1998$

VICTORIA FILHO, R.; CAMARGO, P. N. Efeito de herbicidas nos teores de macronutrientes e nas características tecnológicas da cana-de-açúcar (Saccharum spp.). I - mistura de herbicidas em pós-emergência. Planta Daninha, v. 2, p. $96-107,1980$ 